Etnográfica

Revista do Centro em Rede de Investigação em

Antropologia

vol. 25 (1) | 2021

Vol. 25 (1)

\title{
O turismo e a invenção de uma política: escalas, territórios e governança (Portugal, 1906-1936)
}

The tourism and the invention of a policy: scales, territories and governance

(Portugal, 1906-1936)

\section{Frédéric Vidal}

\section{(2) OpenEdition}

\section{Journals}

Edição electrónica

URL: https://journals.openedition.org/etnografica/9964

DOI: 10.4000/etnografica.9964

ISSN: 2182-2891

\section{Editora}

Centro em Rede de Investigação em Antropologia

\section{Edição impressa}

Paginação: 173-191

ISSN: 0873-6561

\section{Refêrencia eletrónica}

Frédéric Vidal, «O turismo e a invenção de uma política: escalas, territórios e governança (Portugal, 1906-1936)», Etnográfica [Online], vol. 25 (1) | 2021, posto online no dia 05 março 2021, consultado o 28 janeiro 2022. URL: http://journals.openedition.org/etnografica/9964 ; DOI: https://doi.org/10.4000/ etnografica.9964 


\section{O turismo e a invenção de uma política: escalas, territórios} e governança (Portugal, 1906-1936)

\section{Frédéric Vidal}

Este artigo propõe um quadro geral de interpretação do contexto histórico de produção de um discurso político sobre o "turismo" em Portugal durante as primeiras décadas do século XX. Ao longo deste período, e na ausência de políticas institucionais estáveis, uma rede mais ou menos informal de atores sociais ocupa um lugar central na definição da ação pública no domínio do turismo. As condições práticas de elaboração, partilha e difusão de uma linguagem comum tiveram uma grande relevância no processo de formação deste "mundo do turismo". De uma forma mais específica, pretendo aqui frisar a importância que o turismo teve na reflexão sobre o modo de articulação entre ações políticas locais e nacionais, e os limites da ação do Estado. O meu argumento é baseado na análise dos debates em torno da definição do quadro administrativo mais adaptado à implementação de uma política turística que fosse ao mesmo tempo coerente à escala nacional e eficiente à escala local. Este debate atinge o apogeu durante o I Congresso Nacional de Turismo, organizado em Lisboa, em janeiro de 1936.

PALAVRAS-CHAVE: turismo, ação pública, Estado, identidade local, Portugal.

The tourism and the invention of a policy: scales, territories and governance (Portugal, 1906-1936) - This article proposes a general framework for interpreting the historical context of the production of a political discourse on "tourism" in Portugal during the first decades of the $20^{\text {th }}$ century. During this period, and in the absence of a stable institutionalized policies, an informal network of social actors had a central role in the definition of public action in the field of tourism. The practical conditions of elaboration, sharing and diffusion of a common language about tourism had a great relevance in the making process of this "tourism world". More specifically, I aim at emphasizing the importance of tourism in the reflection on the way of local and national political actions must be connected and the definition of the limits of the State action. My argument is illustrated through the analysis of the debates surrounding the definition of the administrative framework best suited to implement a tourism policy at the same time coherent at the national level and efficient at the local level. This debate finds its apogee during the First National Congress of Tourism organized in Lisbon, in January 1936.

KEYWORDS: tourism, public action, State, local identity, Portugal.

VIDAL, Frédéric (fvidal@autonoma.pt) - Universidade Autónoma de Lisboa, CRIA-ISCTE, Portugal. 


\section{UM DOS PRINCIPAIS OBJETIVOS DO ESTUDO DO TURISMO PELAS} ciências sociais, nomeadamente pela antropologia, tem sido a análise crítica das dinâmicas sociais e culturais subjacentes à difusão local das práticas turísticas e à construção dos lugares turísticos (Silva 2004). ${ }^{1}$ A proliferação de estudos de caso sobre a "fabricação" (making) ou a "invenção" de lugares turísticos particulares permitiu documentar a forma como o turismo, enquanto fenómeno cultural, mas também social e económico, transforma a perceção e os usos do espaço local ou regional. Para alcançar este objetivo, convém ultrapassar o "paradigma do impacto", que considera o turismo e os turistas como elementos "perturbadores" e "exteriores" às comunidades locais (Doquet 2010). Se o papel uniformizador do turismo tem sido muitas vezes frisado, este processo enraíza-se também na história de cada território e população local (Boukhris e Chapuis 2016). Para lá das oposições disciplinares, os estudos do turismo têm então ganho em promover uma abordagem que inclua não apenas a pluralidade dos atores sociais envolvidos (habitantes, administração, atores económicos), mas também as dinâmicas que se estabelecem entre eles, seguindo uma perspetiva mais "estrutural" (Guilbert 2012) que tem em conta os recursos existentes nas localidades ou a "qualidade dos lugares" (Stock 2004).

Reencontramos aqui uma dimensão fundamental do turismo como fenómeno global que transforma as relações sociais ou económicas locais e que suscita, da parte dos diferentes atores envolvidos, respostas adaptadas, por vezes conflituais, mas também produtoras de formas de mediação (Monteiro 1993; Cousin 2008; Baptista 2017). É deste ponto de vista que o turismo tem também contribuído para a invenção ou a reconfiguração de uma ação pública. À escala local, a análise dos contextos sociais de emergência de uma ação política no domínio do turismo permitiu descortinar a relação complexa, e por vezes paradoxal, entre turismo e desenvolvimento económico (Guilbert 2012; Baptista 2017). Com a análise crítica de discursos e estratégias políticas foi demonstrado como o argumento do "desenvolvimento local" pode ser mobilizado para justificar a implementação de serviços ou a construção de infraestruturas de lazer que, na realidade, correspondem ao gosto e ao desejo de grupos sociais privilegiados (Cousin 2007; Réau e Poupeau 2007). Os estudos mais recentes sobre os conflitos gerados pela massificação do turismo, os protestos sociais que emergem em contexto urbano e as formas de "antiturismo" têm complexificado e enriquecido esse quadro de análise (Colomb e Novy 2017).

A maior parte dos estudos sobre as políticas turísticas adota o pressuposto de que os conflitos e tensões em torno do turismo e do seu papel transformador

1 Os resultados desta investigação foram discutidos, entre outros fóruns, no âmbito do projeto “Cidades em Mudança: Processos Participativos em Portugal e no Brasil”. Projeto bilateral de intercâmbio entre a Universidade Federal Fluminense e o ISCTE - Instituto Universitário de Lisboa, FCT/Capes, 2016-2018. Agradeço também ao Alexandre Vaz pela leitura crítica e os comentários. 
na vida económica, social ou cultural local (geralmente visto de forma cada vez mais negativa quando avançamos no tempo) estão relacionados com a intensificação do fenómeno, ou seja, com a massificação do turismo a partir dos anos 1950 (Vainikka 2013; Harrison e Sharpley 2017). Esta visão acaba por ser reforçada pelas análises de caráter mais histórico, que frisam geralmente a dimensão "consensual" das primeiras ações políticas na Europa do início do século XX (Bertho-Lavenir 1999) ou, adotando uma posição mais "neutra" (Harrison e Sharpley 2017), documentam a importância que teve o turismo na reconfiguração dos espaços e estilos de vida urbanos a partir da segunda metade do século XIX (Cocks 2001). Os usos ideológicos do turismo foram objeto de análises pormenorizadas, no caso português principalmente no contexto da Primeira República (Lousada e Pires 2010) e do Estado Novo (Cadavez 2017), mas sabemos ainda pouco sobre a maneira como o turismo se tornou um tema de "governança", ou seja, uma questão que marca uma evolução nos modos de governação e no equilíbrio de poderes, nomeadamente à escala local (Stoker 1998; Froger 2006; Boukhris e Chapuis 2016).

$\mathrm{Na}$ Europa das primeiras décadas do século XX, a promoção da "indústria do turismo" gerou numerosas discussões em torno da relação de complementaridade ou de antagonismo entre iniciativas privadas e ações públicas (Beckerson 2002; Zahra 2010). A popularização do turismo incitou à elaboração de medidas de ordenamento dos lugares mais procurados, no sentido de melhorar os transportes e as condições de acolhimento dos visitantes. Em Portugal, desde os primórdios da Primeira República, o processo de "institucionalização" das políticas turísticas acabou por esboçar as bases de uma ação pública, com o objetivo de alargar o campo de intervenção da administração. À escala nacional ou municipal, o poder público empenhou-se na definição de regras e de regulamentos para o uso dos espaços públicos (as ruas, as praias) ou privados (os hotéis) e o enquadramento da difusão das técnicas (o automóvel, a eletricidade) ou dos lazeres (o banho, o jogo) (Lousada e Pires 2010).

$\mathrm{O}$ estudo apresentado neste artigo tem por enfoque o período de emergência das políticas turísticas em Portugal, nas primeiras décadas do século XX. Durante este período, assistimos à constituição de um grupo de atores institucionais e individuais bastante heterogéneo, mas que partilhava o mesmo objetivo de definir um campo de ação legal e operativo (administrativo) para melhorar as condições de desenvolvimento do turismo em Portugal. Este grupo, designado aqui pela expressão "o mundo do turismo", corresponde bastante bem à imagem de "nebulosa" utilizada por Christian Topalov para descrever o movimento reformador em França no início da Terceira República: "Um universo finito, mas de contornos imprecisos [...] um conjunto de objetos organizados em sistemas parciais, mas arrastados num movimento conjunto" (Topalov 1999: 13, tradução minha). As condições práticas de elaboração, partilha e difusão de uma linguagem comum tiveram uma grande relevância no 
processo de formação desta "nebulosa". Este esforço concretizou-se, nomeadamente, através do surgimento de publicações especializadas e da organização de congressos. O que poderemos denominar como a construção de um "quadro cognitivo" (Muller 2005).

De uma forma mais específica, pretendo aqui frisar a importância que o turismo teve na reflexão sobre o modo de articulação entre ações políticas locais e nacionais, e os limites da ação do Estado (Buton 1997). O meu argumento vai ser ilustrado pela análise dos debates em torno da definição do quadro administrativo mais adaptado à implementação de uma política turística, que fosse ao mesmo tempo coerente à escala nacional e eficiente à escala local. Este debate iniciado pela Sociedade Propaganda de Portugal, em 1906, atinge o seu apogeu durante o I Congresso Nacional de Turismo, organizado em Lisboa, em janeiro de 1936.

\section{AMBIÇÃO NACIONAL E POLÍTICAS LOCAIS}

No início do século xx, por ser considerado como um elemento chave e facilmente maleável no processo de afirmação ou reconfiguração das identidades nacionais, o turismo foi objeto de uma atenção particular da parte dos governantes. Em Portugal, a Primeira República e o Estado Novo desenvolveram conceções específicas do turismo nacional, em articulação com projetos políticos e ideológicos mais latos. Sem existirem necessariamente oposições radicais entre essas diferentes conceções, o turismo foi sucessivamente considerado como fonte de educação e de formação do bom cidadão para os republicanos (Lima 1912) e como veículo de divulgação e de validação da ideologia do Estado Novo (Cadavez 2017). No entanto, essas leituras ideológicas nunca chegaram a esgotar o discurso político sobre o turismo. A ação política no domínio do turismo é historicamente moldada por uma tensão entre esses processos nacionais e as exigências práticas e técnicas colocadas pelo desenvolvimento de um turismo internacional na Europa (Williams 2014).

A primeira etapa de institucionalização do turismo pela Primeira República portuguesa, com a criação da Repartição do Turismo, em maio de 1911, tem precisamente por objetivo conciliar o estudo de "caráter técnico e administrativo das questões que interessam o turismo" com um projeto muito mais global de reconfiguração da ação do Estado: "o futuro [...] há de mostrar que às Repartições de Turismo está reservado um papel preponderante, sendo elas o órgão centralizador, perante o qual serão afetas as graves questões de turismo nacional, cabendo-lhes a direção e fiscalização dos complicados serviços que este importa". ${ }^{2}$ A organização da "indústria do turismo" pressupõe criar uma ordem jurídica, na qual a relação entre instituições oficiais e iniciativas 
particulares fica colocada sob a autoridade do Estado: "Essa indústria tem de seguir a ordem natural de obediência às leis fundamentais de administração para que os seus resultados não sejam negativos". ${ }^{3}$

A afirmação do papel organizacional e fiscalizador de um Estado permite valorizar a continuidade da ação pública, para além da eventual oposição entre os regimes políticos sucessivos. Esta continuidade manifesta-se nos diferentes congressos organizados num âmbito nacional ou internacional, verdadeiros "órgãos do turismo", segundo a repartição. ${ }^{4} \mathrm{O}$ primeiro Congresso Nacional de Turismo, acolhido em janeiro de 1936 pela Sociedade de Geografia de Lisboa, constitui uma etapa importante deste processo. Este encontro, organizado 30 anos após a criação da Sociedade Propaganda de Portugal (1906), afirma-se como uma ocasião para fazer um balanço do que tinha sido feito, de bom e de mau, nesta matéria em Portugal ao longo das décadas anteriores. O evento recebe uma larga cobertura pela imprensa nacional, com uma manchete no Diário de Notícias (13 de janeiro de 1936), duas páginas no Diário de Lisboa (13 de janeiro de 1936) e uma página na revista Ilustração (l de fevereiro de 1936), entre outros (Cadavez 2017: 125-128).

O congresso reúne 179 delegados que têm por missão estudar "o problema do turismo em Portugal, sob todos os aspetos que possam interessar à sua organização, orientação, administração e fomento, na Metrópole, nas Ilhas Adjacentes e nas Colónias" (AA.VV. 1936: 19). A lista dos participantes dá uma ideia da diversidade dos atores económicos ou institucionais então envolvidos nessa discussão. Encontramos aqui figuras de destaque do setor do turismo, tais como o empresário Fausto de Figueiredo, grande dinamizador do desenvolvimento da zona do Estoril e um dos principais promotores do turismo internacional em Portugal. Estão presentes ainda as principais figuras do mundo associativo do turismo português através dos dirigentes da Sociedade Propaganda de Portugal e dos representantes das associações profissionais e de trabalhadores do setor, tais como a União Hoteleira de Portugal, o Sindicato Nacional dos Profissionais da Indústria Hoteleira, o Sindicato dos Profissionais da Indústria Hoteleira do Distrito do Porto ou o Grémio dos Industriais de Transportes em Automóveis. Por fim, 49 delegados oficiais de comissões de iniciativas das várias regiões do país foram até Lisboa defender o ponto de vista das localidades que, ao longo dos anos anteriores, tinham vindo a afirmar uma ambição turística, com sucesso diferenciado.

Embora o local onde se realizou o congresso possa contribuir para um forte viés, a lista da origem geográfica dos participantes oferece uma imagem contrastada e mais polarizada deste grupo, que está longe de corresponder a uma representação fidedigna do país na sua diversidade (quadro l). A meio dos anos

3 José Lisboa, "O turismo em Portugal: a transformação de Lisboa”, Revista de Turismo, 57: 66.

4 Relatório do Serviço da Repartição de Turismo, 1912: 60. 
Quadro I

Origem geográfica dos participantes ao I Congresso Nacional de Turismo (1936)

Lisboa

Porto

Estoril

Caldas da Rainha

Coimbra

Vila Nova de Gaia

Cascais

Castelo Branco

Castelo de Vide

Covilhã

Guimarães

Leiria

Manteigas

Praia da Rocha

Santarém

Setúbal

Sintra

Tomar

Vila Real de St. ${ }^{\circ}$ António

Amarante

Aveiro

Barcelos

Benfica

Braga

Caldas de Moledo

Carcavelos

Dafundo

\section{0}

12

7

5

3

3

2

2

2

2

2

2

2

2

2

2

2

2

2

I

1

Entre-os-Rios

Ericeira

Espinho

Faro

Figueira da Foz

Gerês

Guarda

Guimarães

Lagos

Leixões

\section{Moura}

Peniche

Pombal

Ponte de Lima

Ponta Delgada

Portalegre

Póvoa de Varzim

Praia da Granja

Praia de Quarteira

S. Vicente

Sesimbra

Taipas

Torres Vedras

Vila do Conde

Viseu

Total

\section{I}

I

1

1

1

I

1

I

1

1

I

1

1

I

Fonte: AA.VV. (1936).

1930, este "Portugal Turístico" era urbano e marcado por uma sobrerrepresentação dos territórios situados a norte do Mondego. Os "lisboetas" constituíam de longe o grupo mais numeroso, correspondente a metade dos participantes no congresso. O Baixo Alentejo contou apenas com a representação de Moura. O Algarve beneficiou de uma maior presença, sobretudo graças às comissões de iniciativa locais que foram criadas em algumas praias ao longo da década de 1920. Apenas os grandes centros urbanos - Lisboa e Porto - e algumas localidades que tinham afirmado uma vocação turística - Caldas da Rainha, 
Sintra - beneficiam de uma representação mais numerosa e mais diversificada. Mas é sobretudo a importância adquirida pelo Estoril que simboliza melhor as transformações da geografia turística do país desde o final do século XIX.

Este retrato do Portugal turístico na alvorada do Estado Novo dá conta da dimensão ainda parcelar e inacabada do processo de construção de uma organização do setor do turismo à escala nacional. A criação de uma administração local do turismo nos anos 1920 inscreveu-se na continuidade da ação das associações locais - principalmente as delegações locais da Sociedade Propaganda de Portugal -, que surgiram nas primeiras décadas do século XX (Jesus 2014). O processo de desenvolvimento da atividade da sociedade na província foi, no entanto, moroso e limitado. Em 1924, Raul Proença recenseia, no seu Guia de Portugal, 22 delegações regionais da Sociedade Propaganda de Portugal (Proença 1924). Mais do que uma organização estruturada, as delegações locais da Sociedade Propaganda de Portugal constituíam um enredo descontínuo, com contornos relativamente imprecisos, na maior parte dos casos dependentes da boa vontade e do dinamismo de algumas personalidades locais.

Do ponto de vista organizacional, os Touring Clubs europeus e as suas numerosas ramificações regionais serviam de referência. Mas, contrariamente ao que se verificava em França onde, entre 1901 e 1906, os Touring Clubs estiveram na origem da organização de uma rede de comissões (syndicats) de iniciativa local (Bertho-Lavenir 1999), em Portugal a institucionalização de uma rede local de organismos de promoção do turismo deve-se sobretudo à intervenção direta do governo central. Em 1914, é elaborado um primeiro projeto que pretendia descentralizar a ação do Conselho de Turismo, o órgão oficial de promoção da atividade turística, criado em maio de 1911. Foi em 1921 que foram finalmente instituídas as comissões de iniciativa em todas as "estâncias" de turismo (Lei n. ${ }^{\circ} 1152$, de 23 de abril de 1921). O regulamento dessas comissões, publicado em 1923, elenca um elevado número de localidades turísticas, estabelecendo-se certas categorias: praias, estâncias climatéricas, de altitude, de repouso e estâncias de turismo stricto sensu. ${ }^{5}$ A composição dessas comissões segue a mesma lógica das outras entidades do setor turístico criadas a partir dos anos 1910, juntando representantes das administrações locais, do setor associativo (um delegado da Sociedade Propaganda de Portugal, de preferência membro da delegação local ou, na sua ausência, um sócio indicado pela direção nacional) e diferentes atores da vida económica local (hoteleiros, proprietários ou comerciantes). As comissões de iniciativa local conheceram um rápido desenvolvimento entre os últimos anos da Primeira República e o início dos anos 1930. Em 1936, estavam em atividade no país 83 comissões. ${ }^{6}$

5 Lei n. ${ }^{\circ} 1152$ (23 de abril de 1921 ) e Decreto n. ${ }^{\circ} 8174$ (14 de março de 1923).

6 A Organização do Turismo em Portugal, tese apresentada pelo Eng. ${ }^{\circ}$ Carlos Manitto Torres, I Congresso Nacional de Turismo, Lisboa, 1936. 
Temos ainda uma visão muito parcelar da atividade das comissões de iniciativa criadas na década de $1920 .{ }^{7}$ Até à aprovação do Código Administrativo de 1936, a questão da relação entre a administração central, as autarquias e as comissões de iniciativa locais está no centro de um debate bastante aceso. O modo de financiamento das ações locais é um dos principais pontos de desacordo. A legislação aprovada no início da década de 1920 previa que as comissões locais deviam ter um financiamento autónomo, com a aplicação de uma taxa a todos os visitantes. Em maio de 1928, um novo decreto prevê que o financiamento das comissões de iniciativa passe a depender das receitas entregues pelo governo (Brito 2003: 600-603). A partir de 1929, as comissões são sujeitas a um controlo orçamental direto por parte da Comissão Nacional de Turismo. ${ }^{8}$ Essa perda de autonomia prefigura as grandes alterações da organização administrativa do país durante o Estado Novo. Em 1936, o novo Código Administrativo extingue as comissões de iniciativa e integra os órgãos locais de turismo na administração municipal (idem: 648-652). O que, no contexto do Estado Novo, corresponde a uma estatização das políticas locais (Machado 2010: 240).

A nova ordem política e institucional imposta pelo Estado Novo coloca provisoriamente um ponto final na reflexão em torno da ação pública no domínio do turismo e, nomeadamente, do modo de articulação entre os quadros nacional e local. A defesa da autonomia das comissões locais pode ser interpretada como um sinal da influência das ideias regionalistas e municipalistas defendidas pelo movimento republicano desde o final do século XIX (Leal 2006; Alves 2010). A crítica ao centralismo monárquico era um dos temas fortes da propaganda republicana, mas, após 1910, não se traduziu numa alteração significativa do quadro geral de organização dos poderes locais (Alves 2010). Para os republicanos, o turismo representava, no entanto, uma oportunidade para pensar de uma forma mais democrática e harmoniosa a complementaridade entre o poder nacional e o poder local ou municipal. Ao invés, todas as formas de "regionalização" deveriam necessariamente contemplar a questão turística, e não apenas para promover a singularidade de cada província. No final da República, encontramos na imprensa especializada defesas enérgicas da aliança estratégica entre "regionalismo" e "turismo". ${ }^{9}$ O turismo é visto como um poderoso congregador das políticas de ordenamento territorial que

7 Ver, por exemplo, as teses de mestrado de Ricardo Hipólito (2013), sobre as Caldas da Rainha, e de Carlos Nunes (2009), sobre a Figueira da Foz, assim como o trabalho pioneiro de Sandra Silva (2005), sobre a Covilhã.

8 Decreto-Lei n. ${ }^{\circ} 15.465$ (14 de maio de 1928) e Decreto n. ${ }^{\circ} 17.605$ (14 de novembro de 1929).

9 Ver, por exemplo: José Lisboa, "Regionalismo e turismo: dos congressos em projecto devem saír os 'Núcleos Regionais', Revista de Turismo, 95 e 96: 137. 
devem promover ao mesmo tempo o "equilíbrio económico de cada província" e "o progresso geral da Nação". ${ }^{10}$

No Congresso Nacional de Turismo de 1936, diferentes modelos organizacionais estão ainda em discussão. Várias comunicações publicadas nas atas do congresso são acompanhadas de organogramas que estabelecem relações de subordinação ou de controlo entre diferentes repartições e direções administrativas, correspondentes a esferas de ação específicas. O crescimento do turismo no país pressupõe a intervenção de uma administração que se deve constituir num continuum de atores institucionais, do nível nacional ao local (Payre e Pollet 2005). Nesses documentos, que têm apenas uma dimensão prospetiva, dois modelos organizacionais emergem. O primeiro assenta numa organização territorial e uma estrutura administrativa muitas vezes dependente da capacidade de ação do poder central e dos constrangimentos financeiros. É o caso da tese apresentada por José de Penha Garcia, que prevê a criação de cinco regiões turísticas: Norte, Centro, Sul, Insular e Colonial. ${ }^{11}$ Essa divisão do território nacional é meramente funcional e pensada de cima para baixo. Não pode ser entendida como uma vontade de reconhecer autonomia a regiões que teriam a sua própria governança económica ou administrativa. Para o autor desta proposta, é bem claro que a organização regional deve, antes de mais, permitir uma intervenção direta do Estado, por meio de um Conselho Técnico Turístico e de uma Federação Nacional do Turismo concebida como um "órgão corporativo" que estruturaria as atividades turísticas no Estado corporativo português, nos moldes definidos na Constituição de 1933.

O segundo modelo organizacional baseia-se numa divisão e subdivisão das competências técnicas. Carlos Manitto Torres prevê, por exemplo, a criação de três direções que correspondem a campos de intervenção distintos: uma direção de "cultura e estudos" (encarregada da educação, dos museus, da defesa da tradição e do "pitoresco", da cozinha "caraterística" mas também do urbanismo, entre outros aspetos); uma direção de "organização e recetiva" (encarregada dos transportes, da polícia, dos hotéis, dos planos e projetos de obras, etc.); e uma direção de "propaganda e publicidade" (que trataria da recolha das informações e de todas as formas de publicidade interna e externa: cartazes, guias, brochuras, filmes, conferências, etc.). ${ }^{12}$ Esta conceção da governança privilegia a consolidação de um quadro cognitivo comum, resultado de um processo iniciado no final do século XIX.

10 Idem.

11 Algumas Bases para a Organização do Turismo em Portugal, tese apresentada pelo Dr. José Penha Garcia, I Congresso Nacional de Turismo, Lisboa, 1936. É uma das raras intervenções que evoca a existência de territórios coloniais.

12 A Organização do Turismo em Portugal, tese apresentada pelo Eng. ${ }^{\circ}$ Carlos Manitto Torres, I Congresso Nacional de Turismo, Lisboa, 1936. 


\section{O CAMPO DE AÇÃO: MODERNIZAÇÃO TÉCNICA E EXPERTISE}

No início do século XX, o primeiro movimento internacional de institucionalização do turismo corresponde, na realidade, à primeira forma de consciencialização da importância que o turismo tinha ganho no desenvolvimento das sociedades (Heiss 2009). A partir de 1906 - data de fundação da Sociedade Propaganda de Portugal (SPP) - e sobretudo de 1911 - ano de organização do IV Congresso da Federação Franco-Espanhola-Portuguesa de Turismo, em Lisboa, e da criação da Repartição do Turismo -, o mundo do turismo português inscreve-se plenamente nesse processo (Matos, Bernardo e Santos 2011; Jesus 2014). Durante este período, a parte mais visível dessa ação coletiva consiste na recolha de informações posteriormente divulgadas sob a forma de boletins ou de relatórios - como o relatório anual da Repartição de Turismo ou os boletins mensais da Sociedade Propaganda de Portugal, distribuídos aos sócios até 1921 (Proença 1924: 152). Essas publicações têm uma difusão restrita, mas contribuem para impor uma agenda e as bases de uma reflexão coletiva sobre as insuficiências e as ações prioritárias nesta área. Este mesmo tipo de discussões vai surgir também numa revista de maior difusão, a Revista de Turismo, publicada entre 1916 e 1924, que se apresentava como uma "publicação quinzenal de turismo, propaganda, viagens, navegação, arte e literatura”. Esta revista vinha na continuidade da Gazeta dos Caminhos de Ferro, que desde o final dos anos 1880 tinha dado um grande destaque à promoção do turismo em Portugal (Ribeiro 2009).

No seu estudo sobre os primeiros anos da SPP, entre a fundação da associação em 1906 e a criação da Repartição de Turismo pelo governo republicano em 1911, Pedro Cerdeira de Jesus (2014) apresenta uma boa caraterização deste grupo social que lidera o projeto de promoção do turismo em Portugal. A SPP era o "produto das redes de sociabilidade da capital", reunindo homens que "escreveriam nos mesmos jornais, eram sócios da Sociedade de Geografia, da Associação Comercial de Lisboa e da Academia das Ciências, circulavam nas administrações de instituições e empresas" (Jesus 2014: 35). Politicamente diversificado e afastado das lutas partidárias, este grupo estrutura-se em torno do desígnio federador da SPP e da sua função de "catalisadora de melhoramentos, de motor do ressurgimento da nação, ressurgimento que implicaria igualmente os progressos morais e a educação" (Jesus 2014: 32). Neste projeto, os engenheiros surgem como "figuras cimeiras", portadores desse "otimismo que lhes [vem] dos conhecimentos técnicos" (Jesus 2014: 32). Estão omnipresentes nas redes mais ou menos formais de colaboração que se constituem em torno da SPP e das suas publicações. No congresso de janeiro de 1936, ainda constam 17 engenheiros na lista de delegados.

A partilha de uma cultura técnica capaz de orientar o projeto de modernização do território nacional é uma das condições essenciais para o sucesso da 
implementação de uma política turística. Deste ponto de vista, esse "mundo do turismo" inscreve a sua ação nos passos da geração anterior de técnicos e engenheiros envolvidos nos projetos de transformação do espaço nacional (construção de túneis, portos, estaleiros, linhas de caminho de ferro), reivindicando e encenando uma forma de "nacionalismo tecnológico" (Saraiva 2007; Macedo 2012). Durante a segunda metade do século XIX, em Lisboa, os primeiros planos de melhoramento urbano tentam conciliar as problemáticas mais concretas e quotidianas da cidade (saneamento, circulação) com uma visão mais ou menos idealizada de uma cidade "cais da Europa", polo turístico por excelência (Barata 2010; Silva e Sousa 2009). As formas de cooperação e de diálogo entre a esfera técnica e modernizadora do Estado e o "mundo do turismo" são constantes a partir do final do século XIX. Em 1907, Francisco de Paula Botelho publica sob a chancela da SPP um documento intitulado Melhoramentos Urgentes de Lisboa: Plano Geral, no qual apresenta uma visão crítica do sistema de viação na capital e propõe soluções alternativas (Botelho 1907). Ana Barata (2010: 213-220) analisou em pormenor este plano, notando alguma impreparação técnica do seu autor. Apesar das suas limitações, esse documento ilustra a influência dos organismos do turismo na reflexão sobre o pensamento urbanístico na capital.

O "mundo do turismo" das primeiras décadas do século XX não se limita, no entanto, a promover uma continuidade ou uma intensificação do esforço de modernização técnica do território nacional. Esse território turístico deve também ser tornado atraente, acolhedor, confortável e habitável. Com o desenvolvimento de um saber e de uma expertise em termos de planificação e gestão do turismo, assistimos a um rápido alargamento da definição da ação pública nesse domínio. O congresso de 1936 dá conta de uma tentativa de delimitação de um verdadeiro campo de ação coletiva. São principalmente as condições práticas de aplicação das medidas de incentivo ao desenvolvimento do turismo que são discutidas. A síntese das conclusões dos relatores gerais, publicada pelo Diário de Notícias, destaca a urgência da remodelação "radical" dos serviços e da organização do turismo em Portugal: criação de um "comissariado" dotado dos meios orçamentais necessários; criação de uma Federação Nacional do Turismo; elaboração de um Código do Turismo que reúna a legislação em vigor e de um plano nacional que estabeleça as diretrizes da intervenção oficial, para além de uma longa lista de medidas mais circunstanciais, no domínio da "propaganda", dos transportes ou da organização dos diferentes serviços ligados à atividade turística (restauração, hotelaria, etc.). Sugere-se também a "criação de cursos para hoteleiros, guias e intérpretes, corretores e criados, dentro do quadro geral do ensino técnico profissional”. ${ }^{13}$ A profissionalização das 
atividades do turismo é, aliás, um dos temas fundamentais do congresso. Discutem-se as condições sociais de afirmação de novas atividades profissionais, tais como a de guia-intérprete. Mas são também debatidas transformações no exercício de algumas profissões mais antigas: a transformação dos modos de remuneração, por exemplo, com a discussão em torno do abuso da "gorjeta" na restauração. ${ }^{14}$

Mas como passar dessa lista de medidas tão diversas para uma política refletida e contínua? Nesses anos existe um debate em torno da delimitação das funções das comissões de iniciativa. Em poucos anos, a ação das comissões de iniciativa delineou, de facto, novas unidades territoriais. A palavra "território" não é usada nas atas do congresso de 1936, nas quais se prefere a expressão mais neutra de "zona", incorporando o vocabulário que iria ser consagrado pelo Código Administrativo de 1936 (Brito 2003: 600-605). No início dos anos 1920, o poder central limita-se a identificar, inventariar e classificar "estâncias", ou seja, simples lugares ou referências espaciais isoladas. A noção de "zona turística", que nasce da ação das comissões, pode ser entendida como a criação in situ, e pelas práticas, de novos territórios, ou seja, de divisões sociais do espaço, com as suas fronteiras, modos de apropriação (administração) e identidade (Mero 1991).

Na década de 1920, as comissões de iniciativa mais dinâmicas alargaram bastante os domínios e os objetivos das suas atividades. Onde existem, estas divisões territoriais mantêm ligações estreitas com as outras divisões sociais do território nacional, nomeadamente com as divisões administrativas dos concelhos. Mas há que distinguir dois casos: quando as comissões nasceram diretamente do desenvolvimento turístico de um lugar específico ou quando estas vêm conferir um estatuto particular a uma unidade territorial já existente (os concelhos). As praias são exemplos paradigmáticos do primeiro caso. Várias delas foram reconhecidas como território turístico como, por exemplo, as praias da Rocha, da Granja ou da Quarteira. O decreto de 1923 já tinha inventariado mais de 60 "estâncias de praias" no país, a maior parte autónoma em relação à cabeça dos respetivos concelhos. O gosto e os hábitos de veraneio dos atores do "mundo do turismo" marcaram o destino de alguns desses lugares. No início da Primeira República, alguns membros da direção nacional da Sociedade Propaganda de Portugal que costumavam passar uma época do ano em Portimão, tiveram um papel bastante ativo na criação da Delegação da Sociedade Propaganda da Praia da Rocha, uma das primeiras do Algarve, tendo permanecido ainda bastante dinâmica na década de $1930 .{ }^{15}$

14 A Abolição da Gorgeta, tese apresentada por Manuel Mendes Leite Jr., I Congresso Nacional de Turismo, Lisboa, 1936.

15 "A Propaganda no Algarve", Boletim da Sociedade Propaganda de Portugal, 1 1-12, novembro-dezembro de 1912: 103. 
No segundo caso, numerosas comissões são na realidade representantes de um concelho classificado como "estância": tal como Coimbra, Santarém, Covilhã, Vila Real de Santo António e Caldas da Rainha. Às vezes, mas nem sempre, os limites da área abrangida pelas comissões correspondem aos de um concelho. É, por exemplo, o caso da Comissão de Iniciativa da Covilhã, criada em 1929 (Silva 2005). Noutro caso - como em Santarém -, a comissão intervém em vários concelhos. A relação entre os "territórios turísticos" e as outras divisões do espaço local pode então ser vista como desajustada. Luiz Leitão Cravino, presidente da comissão de iniciativa de Manteigas, propõe por exemplo a criação de uma Federação das Comissões de Iniciativa da Serra da Estrela, que juntaria os concelhos que "partilham os seus lugares turísticos" para se "conseguir uma ação harmónica e concertada de todos os povos vizinhos da mencionada Serra". ${ }^{16} \mathrm{O}$ emaranhamento das delimitações administrativas é também discutido no caso de Santarém. Zeferino Sarmento, da comissão de iniciativa local, deplora desta vez que os limites da comissão não respeitem a delimitação do concelho: "Santarém possui no seu concelho as quedas de água de Pernes e as nascentes do rio Alviela (Olhos d'Água), as termas de Alcanhões, o mosteiro de Almoster, a serra e as ruínas do Castelo de Alcanede, locais estes que poderiam atrair os turistas mas que não fazem parte da zona."17

Em 1936, vários autores lamentam o leque demasiado abrangente dos campos de ação das comissões, que acabam por diluir a sua vocação primeira: a valorização turística de um território. Para Zeferino Sarmento, na maior parte dos casos as "comissões de iniciativa não são mais do que comissões de melhoramento urbano" que substituem as câmaras nas suas tarefas de melhoramento do ordenamento do espaço local. ${ }^{18}$ À mesma conclusão chega Carlos Manitto Torres: "Canalizar águas, prover aos esgotos, iluminar, montar a limpeza pública, organizar a vida local, etc., tudo isto e muito mais é 'fazer turismo', ou concorrer para ele, se se está num país desequipado como o nosso. Simplesmente há aqui um equívoco: isso não cabe às Comissões de Iniciativa, mas aos organismos municipais!” 19

O reforço do papel das comissões de iniciativa é, no entanto, visto como algo positivo. Contrariamente às autarquias, cujas políticas não têm necessariamente de obedecer a um programa de ação pensado à escala nacional, a atividade das comissões enquadra-se num "quadro cognitivo" (Muller 2005)

16 Federação das Comissões de Iniciativa da Serra da Estrela, tese apresentada por Luiz Leitão Cravino, I Congresso Nacional de Turismo, Lisboa, 1936: 3.

17 Organização e Ação das Comissões de Iniciativa, tese apresentada por Zeferino Sarmento, I Congresso Nacional de Turismo, Lisboa, 1936: 5.

18 Organização e Ação das Comissões de Iniciativa, tese apresentada por Zeferino Sarmento, I Congresso Nacional de Turismo Lisboa, 1936.

19 A Organização do Turismo em Portugal, tese apresentada pelo Eng. ${ }^{\circ}$ Carlos Manitto Torres, I Congresso Nacional de Turismo, Lisboa, 1936: 13. 
relativamente uniforme e que foi sendo elaborado ao longo dos anos por via das discussões, dos congressos e dos encontros informais entre os atores envolvidos. O principal argumento a favor da criação de instâncias locais de turismo foi precisamente a necessidade de um certo grau de uniformização da ação pública. No Congresso Hoteleiro de 1917, o diretor da Estância Termal das Caldas de Monchique propunha já a criação de "paróquias de turismo", segundo a ideia de que qualquer estância turística "necessita imperiosamente de oferecer, no que toca a serviços públicos locais, todos os recursos que hoje só se encontram nas grandes cidades", e acrescentava ainda que "tais melhoramentos não se podem esperar dos municípios provincianos que desconhecem aquelas exigências e carecem de pessoal competente para as dirigir, bem como de recursos para as satisfazer". ${ }^{20}$

Este confronto entre a "grande cidade" e a mentalidade "provinciana" ocupa um lugar central nesses debates que agitam o mundo do turismo em Portugal durante as primeiras décadas do século XX. Ele remete para um outro tipo de oposição entre a valorização da "autenticidade" e a inevitável "uniformização" das paisagens e dos estilos de vida. Numa famosa conferência proferida em abril de 1912, Sebastião Magalhães Lima - membro fundador da Sociedade Propaganda de Portugal e primeiro presidente do Conselho de Turismo criado em 191 l - define o problema que se tem colocado aos promotores do turismo na Europa nestes termos: "Uniformizaram-se as cidades com as suas avenidas, os seus boulevards, as suas praças públicas e os seus monumentos? Uniformizou-se a vida, com a suas velocidades, as suas modas, os seus costumes, a sua cozinha? Sem dúvida [...] Mas o que se perdeu em pitoresco e em arte, ganhou-se em bem-estar" (Lima 1912: 8). Na década de 1910, o semanário republicano Alma Algarvia acompanha com interesse as atividades das delegações da SPP na região, em Monchique, "uma das pérolas da província algarvia", ou em Lagos, onde o projeto do Grande Palace-Hotel parece ser anunciador de um "brilhante futuro". ${ }^{21}$ Nesses escritos, próximos da SPP, o turismo é descrito como um fator de progresso que permite integrar, por efeito de imitação e contaminação, as localidades de província num mundo moderno. Uma política em matéria de turismo que procura adaptar os espaços do quotidiano ao que é entendido como sendo a sensibilidade e o gosto dos turistas e, principalmente, dos turistas estrangeiros. Esta aliança de circunstância entre o belo, o funcional e o higiénico não é uma novidade (Silva e Sousa 2009). Já era central na reflexão sobre a cidade e o ordenamento dos espaços urbanos produzida durante a

20 Citado por Brito (2003: 486).

21 "As excepcionaes condições do Algarve. Monchique, uma das pérolas da província algarvia”, Alma Algarvia, n. ${ }^{\circ}$ 107, 23 de março de 1913; "Interesse do Algarve”, Alma Algarvia, n. ${ }^{1}$ 143, 14 de dezembro de 1913. 
segunda metade do século XIX. ${ }^{22} \mathrm{O}$ que é novo é a sua difusão fora das grandes cidades (Nahrath e Stock 2012).

A uniformização paisagística dos territórios turísticos é rapidamente assinalada como um perigo. No Congresso Hoteleiro de 1917, José d'Athayde lamentava que "a influência das grandes cidades sobre os pequenos centros [tenha] contribuído pouco a pouco para a desregionalização" (citado por Brito 2003: 480). Podemos ver aqui uma crítica implícita a uma visão demasiado otimista dos efeitos locais do desenvolvimento do turismo, que seria afinal um dos vetores de difusão do "síndroma provinciano" denunciado por Fernando Pessoa uns anos mais tarde e que compreende, entre outros sintomas, "o entusiasmo e admiração pelos grandes meios e pelas grandes cidades; o entusiasmo e admiração pelo progresso e pela modernidade" (Pessoa 1980 [1928]). Mas, no contexto da emergência de políticas de promoção e de mercantilização das identidades locais e regionais (Harp 2001), esta "desregionalização" é sobretudo vista como contraprodutiva e ineficiente.

Em 1912, num dos seus primeiros relatórios, a Repartição do Turismo defendia a promoção da "indústria das curiosidades", indústria do "bibelot", objetos "com caráter local" que o estrangeiro "tanto gosta de comprar". ${ }^{23}$ Alguns anos mais tarde, a Revista de Turismo notava com ironia que de nada servia tentar responder aos "caprichos" dos estrangeiros: "Para o atrahir só há que mostrarlhe o que ainda não tenha visto". ${ }^{24}$ Nos anos 1930, este discurso encontra um grande eco nos promotores da ideologia nacional do Estado Novo, sem que os objetivos concretos das políticas locais sejam alterados (V. Alves 2013).

\section{CONCLUSÕES}

As atas da Congresso de 1936 constituem uma fonte de informação bastante rica para analisar os vários desdobramentos das ações de promoção e de enquadramento do turismo em Portugal em meados dos anos 1930. Nesse documento podemos observar a existência de um relativo consenso sobre a importância do turismo para o desenvolvimento local, sobre o atraso de Portugal neste domínio e sobre as medidas mais urgentes a adotar. Estamos na presença de um grupo de atores sociais que se apresentam como relativamente coesos e que partilham uma mesma linguagem, uma mesma visão ou conceção do desenvolvimento económico. Este discurso aparentemente consensual não pode fazer esquecer a disputa pela liderança dos processos de modernização

22 Ver, por exemplo, as propostas de melhoramento de Lisboa redigidas por Pedro José Pézerat em 1865 (Pézerat 1865).

23 Relatório do Serviço da Repartição de Turismo, 1912: 48.

24 José Lisboa, "O Turismo em Portugal. A transformação de Lisboa”, Revista de Turismo, n. ${ }^{\circ} 57: 66$. 
da administração no que ao turismo concerne durante as primeiras décadas do século XX.

Nesse período, a questão da organização territorial do turismo, e nomeadamente da relação entre administração central e local, foi um dos temas mais vivos das discussões sobre o modo concreto de desenvolvimento de uma política turística em Portugal. Com a afirmação do aparelho administrativo do Estado, a partir dos anos 1940, o debate em torno da autonomia do "mundo do turismo" perdeu acuidade. O que pretendi ilustrar neste artigo foi que, antes de uma institucionalização efetiva das "políticas turísticas", houve uma longa discussão que, com referência constante ao contexto internacional, contribuiu para construir pouco a pouco uma conceção específica do "turismo" e da governança dos "territórios turísticos". Os atores envolvidos nessa discussão pensam os tempos e os espaços do turismo como "territórios" autónomos, sendo essa autonomia vista como a garantia do sucesso da ação pública. Deste ponto de vista, o turismo é necessariamente portador de transformações sociais, económicas e culturais positivas.

Essas ações tiveram efeitos nas perceções globais sobre o território local. São claramente modelos específicos que são promovidos, com uma origem social (burguesia urbana) e geográfica (Lisboa e, mais geralmente, as grandes cidades europeias) marcada. As unidades territoriais que nasceram da ação pública contribuíram para transformar as relações humanas com o espaço, num contexto de mutações culturais e técnicas que incidem tanto ao nível das representações, com a construção de paisagem, sistemas difusos de ideias e de conceções do mundo, como ao nível dos usos, com a transformação material e jurídica das práticas espaciais. 


\section{BIBLIOGRAFIA}

AA. VV., 1936, Actas do I Congresso Nacional de Turismo. Lisboa, s.n.

ALVES, Jorge Fernandes, 2010, "Primeira República, poder local e a saga parlamentar para um novo código administrativo”, Revista da Faculdade de Letras - História, 11 (3): 33-61.

ALVES, Vera Marques, 2013, Arte Popular e Nação no Estado Novo: A Política Folclorista do Secretariado da Propaganda Nacional. Lisboa, Imprensa de Ciências Sociais.

BAPTISTA, João Afonso, 2017, The Good Holiday: Development, Tourism and the Politics of Benevolence in Mozambique. Nova Iorque e Oxford, Berghahn Books.

BARATA, Ana, 2010, Lisboa "Caes da Europa": Realidades, Desejos e Fiç̧ões para a Cidade (1860-1930). Lisboa, Edições Colibri.

BECKERSON, John, 2002, "Marketing British tourism: government approaches to the stimulation of a service sector, 1880-1950", em Hartmut Berghoff, Barbara Korte, Ralf Schneider e Christophe Harvie, The Marketing of Modern Tourism: The Cultural History of the British Experience, 1600-2000. Nova Iorque, Palgrave, 133-157.

BERTHO-LAVENIR, Catherine, 1999, La roue et le stylo: Comment nous sommes devenus touristes. Paris, Odile Jacob.

BOTELHO, Francisco de Paula, 1907, Melhoramentos Urgentes de Lisboa: Plano Geral. Lisboa, A. Rodrigues \& $C^{a}$.

BOUKHRIS, Linda, e Amandine CHAPUIS, 2016, "Circulations, espace et pouvoir - penser le tourisme pour penser le politique”, L'Espace Politique, 28 (1), disponível em < http://journals.openedition.org/espacepolitique/3707 > (última consulta em fevereiro de 2021).

BRITO, Sérgio Palma, 2003, Notas sobre a Evolução do Viajar e a Formação do Turismo. Lisboa, Medialivros, 2 volumes.

BUTON, François, 1997, "Bureaucratisation et délimitation des frontières de l'Etat. Les interventions administratives sur l'éducation des sourds-muets au XIXe siècle”, Genèses, 28: 5-28.

CADAVEZ, Cândida, 2017, A Bem da Nação: As Representações Turísticas no Estado Novo entre 1933 e 1940. Lisboa, Edições 70.

COCKS, Catherine, 2001, Doing the Town: The Rise of Urban Tourism in the United States, 18501915. Berkeley, University of California Press.

COLOMB, Claire, e Johannes NOVY, 2017, Protest and Resistance in the Tourist City. Londres, Routledge.

COUSIN, Saskia, 2007, "L'argument du 'développement local' par le tourisme", Actes de la Recherche en Sciences Sociales, 5 (170): 11-13.

COUSIN, Saskia, 2008, "The nation state as an identifying image: traditions and stakes in tourism policy, Touraine, France", Tourist Studies, 8 (2): 193-209.

DOQUET, Anne, 2010, "La force de l'impact", EspacesTemps.net, disponível em < https:// www.espacestemps.net/articles/force-impact/ > (última consulta em fevereiro de 2021).

FROGER, Géraldine, 2006, "Significations et ambiguïtés de la gouvernance dans le champ du développement durable”, Mondes en Développement, 4 (136): 11-28.

GUILBERT, Christophe, 2012, "Introduction au dossier: actions politiques territorialisées et tourisme", Mondes du Tourisme, 5: 8-12.

HARP, Stephen L., 2001, Marketing Michelin: Advertising and Cultural Identity in TwentiethCentury France. Baltimore, John Hopkins University Press. 
HARRISON, David, e Richard SHARPlEY (orgs.), 2017, Mass Tourism in a Small World. Oxfordshire, Wallingford, e Boston, MA, CABI.

HEISS, Hans, 2009, “Tourism”, em Akira Iriye e Pierre-Yves Saunier, The Palgrave Dictionary of Transnational History - From the Mid-19th Century to the Present Day. Nova Iorque, Palgrave Macmillan, 1021-1025.

HIPÓLITO, Ricardo, 2013, O Turismo nas Caldas da Rainha na Viragem do Século XIX para o Século XX. Lisboa, ISCTE - Instituto Universitário de Lisboa, tese de mestrado.

JESUS, Pedro Manuel Cerdeira de, 2014, A Sociedade Propaganda de Portugal: Turismo e Modernidade (1906-1911). Lisboa, FCSH - Universidade Nova de Lisboa, tese de mestrado.

LEAL, Ernesto Castro, 2006. "A ideia federal no republicanismo português (1910-1926)", Revista de História das Ideias, 27: 25 1-291 , disponível em < https://doi.org/10.14195/2 1838925_27_7> (última consulta em fevereiro de 2021).

LIMA, Magalhães, 1912, Vida Internacional - O Turismo em Portugal: Necessidade de Criar e Desenvolver a Sua Indústria no Nosso Paiz. Lisboa, impressão de Manuel Lucas Torres.

LOUSADA, Maria Alexandre, e Ana Paula PIRES (orgs.), 2010, Viajar: Viajantes e Turistas à Descoberta de Portugal no Tempo da I República. Lisboa, Comissão Nacional para as Comemorações do Centenário da República.

MACEDO, Marta, 2012, Projectar e Construir a Nação: Engenheiros, Ciência e Território em Portugal no Século XIX. Lisboa, Imprensa de Ciências Sociais.

MACHADO, Virgílio Miguel, 2010, Direito e Turismo como Instrumentos de Poder: Os Territórios Turísticos. Vila Nova de Famalicão, Editorial Novembro.

MATOS, Ana C., Maria A. BERnARDO, e Maria L. F. N. SANTOS, 2011 , "A Sociedade Propaganda de Portugal e o Congresso de Turismo de 1911 ”, República e Republicanismo. Congresso Histórico Internacional, Lisboa, disponível em < http://dspace.uevora.pt/rdpc/bits tream/10174/4456/1/ACM\%20MAB\%20Provas\%20para\%20rever.\%202012.12.07. pdf $>$ (última consulta em fevereiro de 2021).

MERO, Guy Di, 1991, "La genèse du territoire local: complexité dialectique et espacetemps”, Annales de Géographie, 100 (559): 273-294.

Monteiro, Pedro M. Prista, 1993, Sítios de Querença: Morfologias e Processos Sociais no Alto Barrocal Algarvio. Lisboa, ISCTE, tese de doutoramento em Antropologia Social.

MULLER, Pierre, 2005, "Esquisse d'une théorie du changement dans l'action publique: Structures, acteurs et cadres cognitifs”, Revue Française de Science Politique, 55 (1): 155$-187$.

NAHRATH, Stéphane, e Mathis STOCK, 2012, "Urbanité et tourisme: une relation à repenser", Espaces et Sociétés, 3 (15): 7-14.

NUNES, Carlos M.F.A., 2009, Figueira da Foz (1930-1960): Apontamentos sobre o Turismo Balnear. Coimbra, Faculdade de Letras da Universidade de Coimbra, tese de mestrado.

PAYRE, Renaud, e Gilles POLLET, 2005, "Analyse des politiques publiques et sciences historiques: quel(s) tournant(s) socio-historique(s)?", Revue Française de Science Politique, 1 (55): 133-154.

PESSOA, Fernando, 1980 [1928], "O provincianismo português", Textos de Crítica e de Intervenção. Lisboa, Ática, 159.

PÉZERAT, Pedro J., 1865, Mémoire sur les études d'améliorations et embellissements de Lisbonne. Lisboa, Imprimerie Franco-Portugaise.

PROENÇA, Raul, 1924, Guia de Portugal - vol 1. Lisboa, Oficinas Gráficas da Biblioteca Nacional. 
REAU, Bertrand, e Franck POUPEAU, 2007, "L'enchantement du monde touristique", Actes de la Recherche en Sciences Sociales, 5 (170): 4-13.

RIBEIRO, Elói de Figueiredo, 2009, "A gazeta dos caminhos de ferro e a promoção do turismo em Portugal (1888-1940)”, Biblio 3W-Revista Bibliográfica de Geografía y Ciencias Sociales, XIV (837), disponível em < http://www.ub.edu/geocrit/b3w-837.htm > (última consulta em fevereiro de 2021).

SARAIVA, Tiago, 2007, "Inventing the technological nation: the example of Portugal (18511898)", History and Technology, 23 (3): 263-273, disponível em < https://doi.org/10.10 80/07341510701300346 > (última consulta em fevereiro de 2021).

SILVA, Álvaro Ferreira da, e Maria Luísa SOUSA, 2009, "In search of the urban variable: understanding the roots of urban planning in Portugal". Métropoles, 6, disponível em $<$ http://journals.openedition.org/metropoles/4029 > (última consulta em fevereiro de $2021)$.

SILVA, Maria Cardeira da (org.), 2004, Outros Trópicos: Novos Destinos Turísticos, Novos Terrenos da Antropologia. Lisboa, Livros Horizonte.

SILVA, Sandra Isabel Pinto, 2005, O Turismo na Serra da Estrela: a Comissão de Iniciativa da Covilhã, 1929-1936. Aveiro, Universidade de Aveiro, tese de mestrado.

STOCK, Mathis (org.), 2004, Le tourisme: Acteurs, lieux et enjeux. Paris, Belin.

STOKER, Gerry (org.), 1998, The New Management of British Local Governance. Londres, Macmillan.

TOPALOV, Christian (org.), 1999, Laboratoires du nouveau siècle: La nébuleuse réformatrice et ses réseaux en France, 1880-1914. Paris, Editions de l'Ecole des Hautes Etudes en Sciences Sociales.

VAINIKKA, Vilhelmiina, 2013, "Rethinking mass tourism", Tourist Studies, 13 (3): 268-286. WILLIAMS, Tom, 2014, "Going places: recent histories of European tourism", Contemporary European History, 23 (2): 295-304.

ZAHRA, Anne Louise, 2010, "A historical analysis of tourism policy implementation by local government", Journal of Tourism History, 2 (2): 83-98.

Receção da versão original / Original version

$2018 / 07 / 20$

Receção da versão revista / Revised version

$2019 / 12 / 09$

Aceitação / Accepted

2020/09/03 